\title{
Design Research on Construction of the Teaching Model of Flipped Class for Yoga Education in Colleges in the Context of Micro Media
}

\author{
Mo Liqiong \\ Wuchang Institute of Technology 430065
}

\begin{abstract}
The continuous integrative development of information technology and education and teaching, as well as the increasing use of micro media make the teaching model of flipped class emerges. Flipped class changes the traditional class teaching model through online video resources, that is, students study on their own prior to class through the learning resources published by teachers, as well as teachers organize discussion and exchange among students in class and evaluate their task completion, thereby helping students achieve further learning and consolidation of knowledge, and providing students with flexible learning space and time. With analysis of the research background of this subject, this paper provides the feasible base of the implementation of yoga education in colleges, illustrates the necessity of practicing flipped class in colleges, and draws the theoretical and practical bases for the study of the subject, thereby building implementation steps for design research on construction of the teaching model of flipped class for yoga education in colleges in the context of micro media.
\end{abstract}

Keywords-The context of micro media; Yoga education; Flipped class; Teaching model; Design research

\section{INTRODUCTION}

Under the impact of the rapid development of information technology, the education and teaching model is undergoing tremendous changes, so it is necessary to alter the traditional classroom teaching model in order to adapt to the trend of social education, the teaching model of flipped class becoming the preferred form of change. Flipped class originated in a mountain school in Colorado of America, where in order to solve the problem that students missed courses for various reasons, a chemistry teacher uploaded to the Internet videos combining explanation and teaching materials presentations to help the absent make up classes, flipped class developing from this. As a new teaching method, flipped class has become an important form of study and work in colleges. Carrying out yoga in colleges needs an effective and convenient teaching method to support it; especially in the current situation of popular micro media, flipped class has become the preferred teaching mode for the development of yoga education in colleges. This paper mainly focuses on the design research of the flipped class teaching model of yoga education in colleges in the context of micro media, analyzing the research and implementation of this class.

Mo Liqiong, a female from the Zhuang ethnic group, was born in January 1982 in Guilin, Guangxi Province. With a master's degree, she is an assistant professor on Science of Physical Education and Training at Wuchang Institute of Technology.
II. A NEW BREAKTHROUGH IN THE FLIPPED ClASSES TEACHING Model of Yoga EdUCATION IN COLLEGES IN THE

\section{CONTEXT OF MICRO MEDIA}

Due to its characteristics, the micro media has a significant impact on the implementation of the teaching model of yoga education in colleges. By building a platform for online learning and communication, a new teaching model of yoga education in colleges has been created-the flipped class teaching mode. Compared with the traditional teaching mode, the flipped class teaching model has innovated the new media form of class education and expanded the practice of yoga education.

(1) Construct yoga-themed micro-media exchange platform and enhance the initiative of the flipped class teaching model. Under the traditional teaching mode, it is limited for students to achieve knowledge of yoga and communicate with teachers in time and depth, so teachers find it difficult to master students' learning status timely and accurately, while with micro-media platforms such as Weibo and WeChat, students can express their emotions, speak their minds, and break the binding nature of teaching [1]. Teachers or yoga educators can pay attention to the topics frequently discussed by students through yoga-based micro-media platforms to understand the students' lack of knowledge about yoga, so as to master students' learning trends and formulate accurate and reasonable teaching plans, thereby achieving the maximization of teaching effectiveness.

(2) Set up a network platform of yoga information resources, providing rich teaching resources for the flipped class teaching model. In the implementation of the traditional teaching mode, the main source of knowledge for the students is the teacher's explanation and class-related teaching materials. However, in the non-classroom time, resources for learning yoga can be collected by students is relatively limited [2]. Teachers can upload videos and learning materials related to yoga teaching on a sharing platform for dedicated yoga information resource, and students can select corresponding resources according to their own specific needs to maximize the utilization of resources. This way can also provide rich teaching materials for the implementation of flipped class resources, enhancing class fun and expertise. 


\section{NECESSITY OF IMPLEMENTING THE FLIPPED CLASS TEACHING MODEL FOR YOGA EDUCATION IN COLLEGES}

\section{A. Flipped Class for Yoga Education to Achieve Stratified Teaching}

The current main teaching model of yoga education in colleges is the traditional class teaching, that is, teachers in the classroom explain yoga knowledge and the essentials of action, as well as students learn new knowledge in accordance with teachers' thinking and learn yoga moves under the guidance of teachers. However, under this teaching mode, teachers can not take all students into account, deviations may occur in the guiding direction, and students with poor basic skills can not keep up with the teaching pace of teachers, ultimately losing their interest in learning yoga. Carry out the flipped class teaching model in yoga education. Teachers release teaching videos and learning resources of yoga moves; students conduct targeted learning and practice in line with their own learning. Meanwhile, with relevant teaching software, teachers can supervise the learning of students, understand whether students' self-learning yoga moves are correct and smooth, as well as know students' learning progress and quality to practice stratified teaching so that students, no matter how their base is, are able to learn yoga moves appropriate to their own ability, and teaching quality can be improved [3].

\section{B. Flipped Class for Yoga Education Able to Break the Time Limit}

Traditional classroom teaching is limited to 40 to 45 minutes. Due to time constraints, teachers may not be able to complete the teaching contents according to teaching plans, and it is also possible for students to be absent from school because of physical discomfort and accidents, but yoga learning is a sustained process, so any absence can result in weakening the learning effect of yoga, which leads to differences in the progress of learning among students and does harm to the continuity of yoga teaching. The flipped class teaching model effectively solve this problem, because students can choose their own study time and place. Even if they miss some part of learning contents for some reason, but can also use teaching videos to catch up with the progress of learning, thereby ensuring that every yoga study is of the highest efficiency.

\section{Flipped Class for Yoga Education Able to Effectively Achieve the Teaching Linkage}

The traditional classroom yoga teaching model includes preparation of class, learning of new content study, teachers' summaries and after-class review. Although there is the preclass preview, teachers can not fully understand students' cognition of new yoga movements. Therefore, there may be major deviations from yoga movements in the teaching process. Moreover, teachers do not know the conditions of students' mastery of yoga moves in class and after-class review, and teaching and learning can not achieve effective convergence, while the flipped class teaching mode can help teachers through the learning supervision system to effectively grasp how students master yoga knowledge and moves, timely solve problems occurred in learning and practicing yoga movements, as well as grasp the focus of yoga teaching to achieve a better teaching linkage [4].

\section{DESIGN OF FliPPED Class FOR Yoga TEACHING IN COLLEGES IN THE MICRO-MEDIA CONTEXT}

\section{A. Teaching Model Design Principles of Flipped Class for Yoga Education}

\section{1) Task-driven Principles}

Task drive is a process enabling learners in some practical life-related task scenarios, through the completion of the designated tasks to learn knowledge, increase skills and internalize abilities. The development of flipped class for yoga education relies on online video lessons, and flipped class activities are mainly driven by the teacher-designed "task learning" method, that is, teachers will design yoga knowledge and learning difficulties needed to be mastered into real and daily life-related tasks presented by video formats, guiding students to learn yoga moves autonomously and comprehensively sorting yoga knowledge. A task may include a number of yoga moves and knowledge points; students can accomplish their tasks as well as integrate and apply their own yoga knowledge frame. At the same time, they can make a selfexamination on their own yoga skills, filling leak.

\section{2) Micro Video-based Principle}

Nowadays, with the universal development of informationization, online videos have become the most popular learning method for university students. According to the survey data, the vast majority of students like resources like online videos, graphs and texts, and only a handful of students like the printed text resources. Micro class, a new online video learning way, is popular among a large number of teachers, students and experts, so the design of yoga education flipped class mainly depends on the micro-class form, aided by some network resources links.

\section{3) Multiple Evaluation Principle}

Teaching evaluation is an important part in the process of teaching activities, indicating that with teaching objectives as the basis and a reasonable evaluation method, according to scientific and reasonable evaluation criteria, the process and results of teaching activities are evaluated, value judgments and effectiveness of teaching activities given, and existing problems raised in order to improve in time. After releasing tasks and contents of yoga study, teachers can formulate a reasonable evaluation mechanism which can be carried out from several aspects of yoga study, such as limb coordination, move smoothness, respiration smoothness, accuracy of important and difficult movements and so on, thereby appraising students' learning quality, in order to adjust the progress of yoga teaching and achieve the maximum learning effectiveness. 


\section{B. Design Steps for the Yoga Education Flipped Class Teaching Model}

\section{1) Topic Selection}

After a long period of yoga development and spread, yoga has evolved a variety of learning contents, including dance, gymnastics, music, martial arts and meditation. The flipped class teaching model does not fit every lesson and every learning content, so teachers should make reasonable use of this teaching model on the basis of yoga characteristics, yoga teaching goals, the distribution of key and difficult points of yoga, and students' understanding of yoga, thereby gaining the most effective teaching effect [5].

\section{2) Analysis of College Students}

Yoga has gradually been accepted by Chinese people, and college students' understanding of yoga is the basis for the implementation of the flipped class teaching model for yoga education. Only by in-depth understanding of students' cognitive basis can the accurate orientation be found in yoga education and the effective teaching model be implemented. Meanwhile, according to the relevant learning and test system, teachers can fully understand students 'pre-lesson preparation and after-class practice, as well as grasp moves not mastered by students or difficulty moves in practice. In this way, teachers can further their teaching and solve the problem.

\section{3) Teaching Methods and Teaching Strategy Design}

\section{a) Stratified Teaching Method}

With continuous yoga teaching practice and a large amount of yoga teaching experience, combined with the characteristics and requirements of yoga teaching, the stratified teaching method is proposed. Before class, a teacher asks students to do some strong warm-up exercises to make their body temperature rise slightly and prepare for the class study; in the formal teaching, students' breathing frequency matching moves should be emphasized, and the key points is to help students relax and enjoy the emotional experience; after class, carry out yoga learning mainly through yoga clubs and yoga interest communities.

\section{b) In-class Flipped Strategy}

In the traditional classroom teaching process, the in-class flipped strategy can be used, that is, in the initial period of class, students watch yoga learning videos on their own and practice yoga in accordance with these videos, and then, in the rest of class, teachers organize exchange and sharing activities, in which firstly, students solve problems in the learning process by themselves and then share study notes, as well as finally teachers review the learning focus, properly advising students about unsolved problems, testing learning results and summarizing the lesson. This method is suitable for the class where students lack learning initiative [6].

\section{c) Teacher-student Role Exchange Strategy}

For some basic yoga courses with simple moves, the teacher-student role exchange strategy can be employed, that is, students act as "teachers", learning contents of this lesson by themselves and then teach knowledge from a teacher's point of view, thereby helping students to systematically summarize and comprehend the content of their study. Teachers will give timely advice to students in their "teaching" process, correct their nonstandard moves and help them to effectively learn and comprehend the essence of yoga.

\section{4) Design of Teaching Activities in Flipped Class}

\section{a) Problem Guidance}

On the basis of students' existing knowledge of yoga and with yoga teaching contents, teachers put forward some relevant questions to students. The problem design involves many aspects. Teachers should consider different levels of students and satisfy their needs as much as possible. Meanwhile, the problem design needs to be from the superficial to the deep, guiding students to deeply learn yoga knowledge. Before class, students preview yoga moves and knowledge by themselves, learning the problem-related yoga moves; at the same time, teachers will make their own teaching videos and release these videos to the relevant learning platform, summarizing key points in class, illustrating difficult moves step by step, urging students to practice, and providing students with quality learning resources. In the design of flipped class for yoga education, teachers guide students to actively participate in previewing yoga moves and key knowledge, as well as self-learning activities. Students are encouraged to choose resources for yoga study by themselves, complete yoga study task assigned by teachers, and master specific yoga moves or the yoga breathing exercise method, teaching goals achieved; in the face-to-face learning of the classroom, teachers should guide students to actively participate in discussing and exchanging the understanding of yoga moves and learning notes.

\section{b) Video Watching}

Students are free to choose the time and place to watch yoga learning videos released by teachers. According to teachers' pre-class questions, they learn systematically. Students understand the key and difficult points of learning, master exercise essentials and the knowledge framework, having a comprehensive study and comprehension in solving the problem; they focus on remembering and practicing key and difficult points required by teachers in videos, thereby achieving purposeful learning. In the process of self-study, the problem of exercise essentials difficult for students to grasp is timely solved through exchange and study among students, or reflected in the supervising system of the learning platform, or students consult teachers about this problem online. Meanwhile, students can send their practice videos to each other, and students have mastered can give advice and opinions to those haven't, thereby achieving common learning and progress, which is an important part of the implementation of the flipped class teaching model and the first time for showing that students internalize yoga moves and knowledge. 


\section{c) Exchange and Discussion}

In the face-to-face communication and discussion of class, first of all, according to the data provided by the learning and supervising platform, teachers give new guidance and teaching to yoga moves hard for students to master in their learning. Secondly, correct students' nonstandard moves in their practice, focus on teaching yoga meditation and its breathing method to achieve an organic combination of yoga moves and this method, and guide students to appreciate the essence of yoga. Finally, design tasks targeting students' unfamiliar moves, students consolidate difficult points again through exchange discussions, and continuous practice.

\section{d) Consolidation and Development}

No matter what knowledge is learned, it is necessary to consolidate and develop the knowledge learned, especially the study of yoga knowledge. Yoga learning has its coherence and systematicness, so long-term practice and consolidation is required to achieve proficiency in application. Students can upload their yoga practice videos to the video learning platform to show what they have learned. The best students can provide other students with yoga practice experience [7]. At the same time, in the consolidation of knowledge, attention should be paid to expand the knowledge. Students can acquire more and deeper yoga knowledge through various search engines and online databases, expanding their horizons and understanding of yoga, as well as systematically summarizing and mixing yoga knowledge and exercise essentials have mastered by themselves, thereby achieving three times' internalization and study of yoga.

\section{CONCLUSION}

Through the systematic analysis and elaboration of the design research for yoga education flipped class in college in the context of micro media, a reasonable design method and procedure are obtained. From the current practice research, the implementation of flipped class has achieved some success. This study only conceives a teaching model, having not focused on studying some concrete practical problems, such as the effect of self-study by students before class and the problem of whether students' problems in yoga study are solved timely and effectively. Any kind of teaching models has its own shortcomings, and the flipped class teaching mode is no exception. We should rationally analyze the advantages and disadvantages of this teaching model, develop its advantages, and avoid its limitations, thereby truly maximizing effect of this model and adding new vitality to college classroom learning.

\section{REFERENCES}

[1] Liu Rui, Wang Haiyan. Design and Practice of the "Flipped Class" Teaching Model Based on Micro Class [J]. Modern Education Technology, 2014, (05): 26-32.

[2] Zhou Xiaobo, Lei Xia, Ren Guocan.Study on the Teaching Model of Flipped Class Based on Micro Class in Project Curriculum [J]. Eeducation Research, 2016, (01): 97-102.

[3] LI Xiaodong, Cao Honghui. Research on the Flipped Teaching Model Based on Micro Class-A Case Study of English Cinema Class in University [J]. Modern Education Technology, 2015, (09): 70-76.

[4] Lu Haiyan. Feasibility Analysis of Application of "Flipped Class" Model Based on Micro Class in College English Teaching [J] Media in Foreign Language Instruction, 2014, (04): 33-36.

[5] Cao Yuna. Application Study of the Micro-class Teaching Model Based on the Concept of "Flipped Class"[J]. Journal of Dali University, 2015, (07): 89-92

[6] Xie Yongpeng, Xu Yan. The Flipped Class Teaching Model Supported by Micro Class in Vocational Colleges. Modern Education Technology, 2015, (07): 63-67.

[7] Guo Shaoqing, Yang Bin. Study of Improvement by "Convergent Evolution" Teaching Design of Micro Class in Colleges for the Flipped Class Teaching Strategy [J]. China Educational Technology, 2014, (04): 98-103. 